\title{
Lactobacillus vaginalis
}

National Cancer Institute

\section{Source}

National Cancer Institute. Lactobacillus vaginalis. NCI Thesaurus. Code C123496.

A species of Gram-positive, rod shaped, facultatively anaerobic, heterofermentative bacteria in the phylum Firmicutes that occur singly or in pairs or short chains. This species is nonmotile and non spore forming. L. vaginalis was isolated from the vaginas of patients suffering from trichomoniasis. 